\title{
Heterogeneous Photocatalytic Click Chemistry
}

\author{
Bowen Wang ${ }^{\ddagger a, b}$, Javier Durantini ${ }^{\ddagger a}$, Jun Nie*b, Anabel E. Lanterna*a and Juan C. Scaiano*a \\ a Department of Chemistry and Biomolecular Sciences and Centre for Catalysis Research and Innovation, University of Ot- \\ 4tawa, Ottawa, Ontario, Canada K1N 6N5. \\ b State Key Laboratory of Chemical Resource Engineering, Faculty of Science, Beijing University of Chemical Technology.
}

Supporting Information Placeholder

\begin{abstract}
Copper-doped semiconductors are designed to photo-assist the alkyne-azide cycloaddition catalysis by $\mathrm{Cu}(\mathrm{I})$. Upon irradiation, injection of electrons from the semiconductor into copper oxide nanostructures produces the catalytic $\mathrm{Cu}(\mathrm{I})$ species. The new catalysts are air and moisture tolerant and can be readily recovered after use and reused several times.
\end{abstract}

Click chemistry (as in Scheme 1) is typically a thermal process efficiently catalyzed by $\mathrm{Cu}(\mathrm{I})^{1}$ or by copper nanostructures..$^{2}$ In a recent publication we demonstrated that the process involves 'truly' heterogeneous catalysis ${ }^{3}$ as opposed to examples where heterogeneous systems act as suppliers for soluble catalysts; in such cases the advantages of heterogeneous chemistry are defeated by the leaching of active materials. ${ }^{4}$ A commercial copper-on-charcoal catalyst is also available for click chemistry, ${ }^{5}$ which in spite of its usefulness in organic chemistry, contains less than $0.003 \%$ active surface. ${ }^{6}$ We report here on a heterogeneous, photoactivated catalyst for the click reaction, specifically for the Huisgen cycloaddition of azides and terminal alkynes. Further, this makes catalyst separation and re-use straightforward. In fact, there have been a few interesting reports of "photo-click" chemistry. Some of them involve photoactivation of an organic reagent, ${ }^{7}$ while others use organic photoreducing agents to convert soluble $\mathrm{Cu}(\mathrm{II})$ to $\mathrm{Cu}(\mathrm{I})$, the active catalyst. 8;9 The latter approach can afford more flexibility, as it could be largely independent of the detailed structure of the substrates.

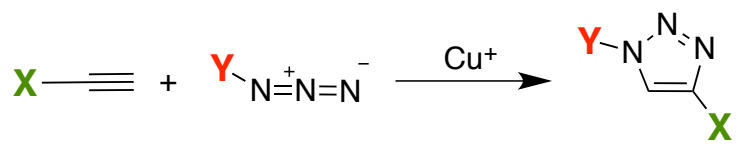

Scheme 1: Gopper-catalyzed azide-alkyne cycloaddition reaction (GuAAG).

The use of light combined with reusable heterogeneous catalysts reduces adverse environmental effects and thus accommodates some of the key strategies of green chemistry.

In this contribution we report that semiconductors with band gaps within the 3-3.5 eV range (such as $\mathrm{TiO}_{2}$ and $\mathrm{Nb}_{2} \mathrm{O}_{5}$ ) decorated with $\mathrm{CuO}_{x}$ nanostructures serve as effective photoactivated click catalysts. Earlier reports include a catalyst with copper hydroxide supported on alumina and titanium oxide, ${ }^{10}$ but where thermal click-reactions required $60{ }^{\circ} \mathrm{C}$ under oxygen-free atmosphere. Other articles describe applications of
$\mathrm{Cu}$ on $\mathrm{TiO}_{2}$ for water splitting, ${ }^{11} \mathrm{CO}_{2}$ photoreduction or for biomedical research, ${ }^{12}$ but to the best of our knowledge, not to photoinitiated catalytic organic reactions. In a related article Bowman et al. ${ }^{9}$ explored the use of suspended $\mathrm{TiO}_{2}$ to reduce $\mathrm{Cu}(\mathrm{II})$ in solution; while the system worked, it was dismissed as impractical for the imaging applications under study. In a recent review, Pale et al. covered numerous methods involving heterogeneous catalysis of click chemistry that have been, or are currently being developed; ${ }^{13}$ surprisingly, none of them involves photo-activated catalysis.

This work was undertaken with the goal of developing a hybrid catalyst as it is illustrated in Figure 1 for $\mathrm{TiO}_{2}$ (it is similar for $\mathrm{Nb}_{2} \mathrm{O}_{5}$ ) decorated with copper nanoparticles, mainly present as oxides (vide infra). When supported on $\mathrm{TiO}_{2}$, the conduction band of $\mathrm{CuO}$ is about $0.3 \mathrm{eV}$ lower than for $\mathrm{TiO}_{2}$ (note that exact gap will depend on particle size), making the electron transfer shown quite favorable. ${ }^{14}$ For both semiconductors, excitation in the band gap region (normally in the UVA region, see Figure S1) promotes a valence band electron to the conduction band. Under normal circumstances electron-hole recombination is a relatively fast process unless either electron or hole is trapped; in our case $\mathrm{CuO}$ on the surface can trap the electron, yielding $\mathrm{Cu}(\mathrm{I})$, Figure 1.12;14-16 Electron donors can trap the hole and in the process hinders the recombination; amines and alcohols can perform this role (vide infra). In other systems the electron can be trapped by $\mathrm{O}_{2}$ and the hole by water in well understood processes, particularly in the case of $\mathrm{TiO}_{2},{ }^{12 ; 17}$ although there are also a few examples involving $\mathrm{Nb}_{2} \mathrm{O}_{5}{ }^{16,18}$ There are examples ${ }^{12}$ where taking advantage of the reduced recombination rates, the electron, the hole, or both are trapped by species in solution, including the solvent itself. 14 The quantum yields of these processes are limited to $<1$, as one photon can only cause one electron to be promoted and at best one chemical change can take place involving the surface of these materials. In our system the effect of excitation is amplified, as photoexcitation leads to the generation of one catalytic site on the surface (i.e., a $\mathrm{Cu}(\mathrm{I})$ site) capable of multiple catalytic events until recombination inexorably takes place.

In order to test the validity of our hypothesis, we prepared $\mathrm{CuO}_{\mathrm{x}} @ \mathrm{TiO}_{2}$ and $\mathrm{CuO}_{\mathrm{x}} @ \mathrm{Nb}_{2} \mathrm{O}_{5}$ and used the reaction between $\mathbf{1 a}$ and $\mathbf{2 a}$ as a model system (Table 1). The synthesis of nanoparticles decorating the semiconductors was achieved insitu using benzoin I-2959 as a source of reducing ketyl radicals, as shown in scheme $\mathrm{S} 1.19$ This normally produces the metal nanoparticles and in the case of copper, air exposure oxidizes them to $\mathrm{CuO}$, a process that has been characterized earlier. ${ }^{14}$ 
The early generation of low oxidation states of copper $(\mathrm{Cu}(0)$ or $\mathrm{Cu}(\mathrm{I})$ ) is clearly evidenced by the brownish color of the materials, which in the case of $\mathrm{TiO}_{2}$ is only visible before the samples are exposed to air, then they turn to light gray, characteristic of supported $\mathrm{CuO}$ (Figure S2). The XPS spectrum of $\mathrm{CuO}_{\mathrm{x}} @ \mathrm{TiO}_{2}$ shows the characteristic satellites peaks of $\mathrm{Cu}(\mathrm{II})^{20}$ between $945-940 \mathrm{eV}$ further confirming the presence of $\mathrm{CuO}$. In the case of $\mathrm{CuO}_{\mathrm{x}} @ \mathrm{Nb}_{2} \mathrm{O}_{5}$ more reduced $\mathrm{Cu}$ species are present initially (Figure S3), although differentiation between $\mathrm{Cu}(\mathrm{I})$ and $\mathrm{Cu}(0)$ is not accurate by this technique. ${ }^{21}$ $\mathrm{Cu}(\mathrm{I})$, if present, was below the limit of detection of our Raman spectrometer. The $\mathrm{Cu}$ loading has been determined by ICP-OES analysis and is 2.51 and $2.04 \mathrm{wt}^{\%} \%$ for $\mathrm{CuO}_{\mathrm{x}} @ \mathrm{Nb}_{2} \mathrm{O}_{5}$ and $\mathrm{CuO}_{\mathrm{x}} @ \mathrm{TiO}_{2}$, respectively. The analysis of SEM and STEM images indicates that nanoparticles deposited on $\mathrm{TiO}_{2}$ are considerably smaller than those on $\mathrm{Nb}_{2} \mathrm{O}_{5}$ (See $\mathrm{SI})$.

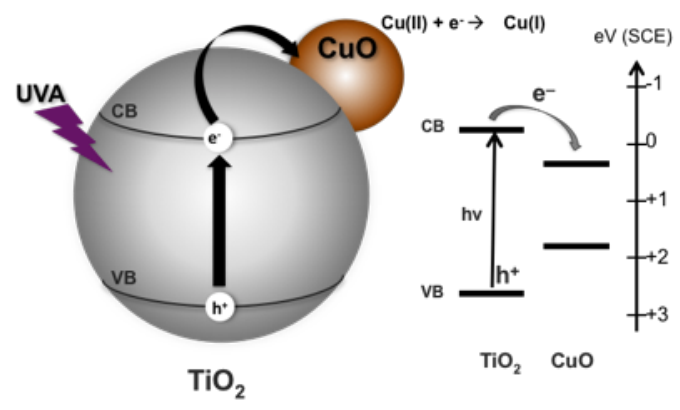

Figure 1. Proposed mechanism of electron transfer from the excited semiconductor to $\mathrm{CuO}$ nanoparticles forming catalytic $\mathbf{C u}(\mathbf{I})$.

In order to evaluate the efficiency of the photocatalytic activity of $\mathrm{CuO}_{\mathrm{x}} @ \mathrm{Nb}_{2} \mathrm{O}_{5}$ for the copper catalyzed azide-alkyne cycloaddition (CuAAC) a series of experiments were performed to optimize the reaction conditions (Table 1). The reaction was tested with different polar solvents and comparing the use of amines and alcohols as co-catalysts. For most CuAAG reactions the addition of amines is anticipated to protect and stabilize copper (I) from oxidation. ${ }^{13 ; 22}$ We believe the main role of the amine here is to act as a hole-scavenger and hence the reaction is expected to work with other sacrificial electron donors $(\mathrm{ED})$. Indeed, for $\mathrm{CuO}_{\mathbf{x}} @ \mathrm{Nb}_{2} \mathrm{O}_{5}$ the reaction works very well when amine is replaced by 2-propanol, although the same is not true for $\mathrm{CuO}_{\mathrm{x}} @ \mathrm{TiO}_{2}$, where the alcohol effectiveness as a hole scavenger is inferior (Figure S9). There are literature precedents showing the superior catalytic activity of $\mathrm{Nb}_{2} \mathrm{O}_{5}$ towards alcohol oxidation. ${ }^{23}$ Experiments performed in the absence of an ED can also lead to good yields while the reaction rate slows down as shown in Figure 2 (and Figure S12). Control experiments in the absence of catalyst or in the presence of $\mathrm{TiO}_{2}$ or $\mathrm{Nb}_{2} \mathrm{O}_{5}$ were also performed but no click reaction was detected.
Table 1. Solvent and the electron donor (ED) effect on the photocatalytic $\mathrm{CuAAC}$ using $\mathrm{CuO}_{\mathbf{x}} @ \mathrm{Nb}_{2} \mathrm{O}_{5}$ as catalyst.

\begin{tabular}{|c|c|c|c|c|}
\hline & & $\begin{array}{r}\mathrm{CuO}_{x} \mathrm{C} \\
\text { Solve }\end{array}$ & & \\
\hline & \multirow{2}{*}{ Solvent } & \multirow{2}{*}{ ED } & \multicolumn{2}{|c|}{$\%$ Yield of $3 \mathrm{a}$} \\
\hline & & & Light $[\mathrm{a}]$ & Dark \\
\hline 1 & $\mathrm{CH}_{3} \mathrm{CN}$ & TEA & 28 & 5 \\
\hline 2 & $\mathrm{H}_{2} \mathrm{O}$ & TEA & 35 & 4 \\
\hline 3 & EtOH & TEA & 34 & 5 \\
\hline 4 & $\mathrm{THF}$ & TEA & 90 & 15 \\
\hline 5 & $\mathrm{THF}$ & PMDTA & 83 & 13 \\
\hline 6 & $\mathrm{THF}$ & 2-propanol[b] & 96 & 4 \\
\hline 7 & $\mathrm{THF}$ & -- & 58 & ND \\
\hline
\end{tabular}

Reaction conditions: $1.2 \mathrm{mmol} \% \mathrm{Cu}$, azide/alkyne/ED (1:1:1), RT, $6 \mathrm{~h}$. $\mathcal{N}, \mathcal{N}$,'N, , $\mathcal{N}$ '-Pentamethyldiethylenetriamine (PMDTA), Triethylamine (TEA). Yields were calculated by ${ }^{1} \mathrm{H}$ NMR in $\mathrm{CDCl}_{3}$. [a] UVA irradiation at $21.4 \mathrm{~W} / \mathrm{m}^{2}$. [b] $5 \mathrm{mmol}$.

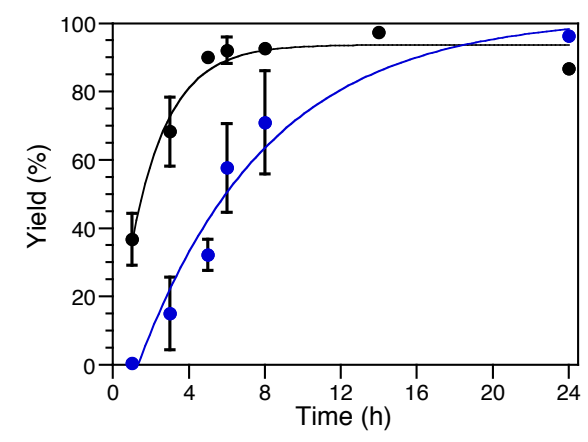

Figure 2. Kinetic study of the photocatalytic reaction of $1 a$ and $2 a$ in THF in the presence (black) and in the absence (blue) of TEA using $\mathrm{CuO}_{\mathbf{x}} @ \mathrm{Nb}_{2} \mathrm{O}_{5}$ as photocatalyst.

Overall, the reaction conditions that best suit both materials (Table 1, entry 4 and Figure S9) were chosen to study their catalytic activity. The kinetic study of the reaction between $\mathbf{1}$ and $\mathbf{2}$ is shown in Figure 3. Interestingly, under dark conditions the catalysts show slightly different activity; $\mathrm{CuO}_{\mathrm{x}} @ \mathrm{TiO}_{2}$ is inactive, while $\mathrm{CuO}_{\mathrm{x}} @ \mathrm{Nb}_{2} \mathrm{O}_{5}$ shows a small but not negligible amount of products, probably due to the nature of the catalytic copper species present in the latter. The presence of some reduced $\mathrm{Cu}$ species, as confirmed by XPS analysis, should favor some reaction under dark conditions for $\mathrm{CuO}_{\mathrm{x}} @ \mathrm{Nb}_{2} \mathrm{O}_{5}$. Both catalysts reach ca.90\% yield after $5 \mathrm{~h}$ UVA irradiation. If the light is turned off, the catalysis yields are reduced, suggesting that $\mathrm{Cu}(\mathrm{I})$ transient needs continued irradiation for its activity level to be maintained (Figure 4). Although greatly reduced, some reactivity remains for some time after the light is turned off. 


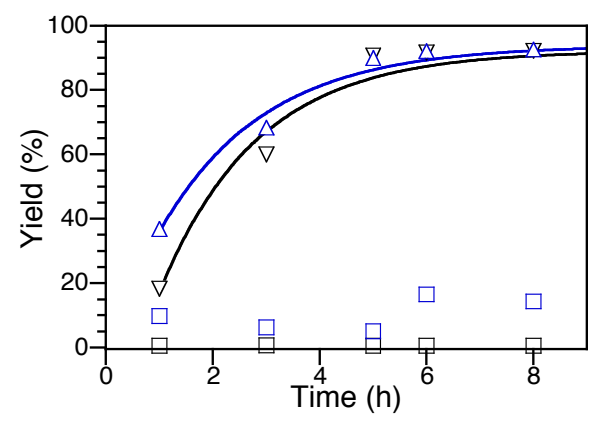

Figure 3 Kinetic study of the photocatalytic reaction of $1 a$ and $2 a$ in THF under dark $(\square)$ and upon UVA irradiation $(\Delta \& \nabla)$. Black: $\mathbf{C u O}_{\mathbf{x}} @ \mathbf{T i O}_{2}$. Blue: $\mathbf{C u O}_{\mathbf{x}} @ \mathbf{N b}_{2} \mathrm{O}_{5}$.

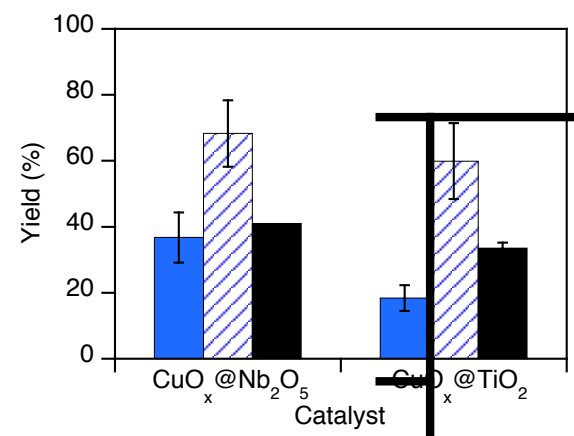

Figure 4. Yields obtained for each material after irradiation for $1 \mathrm{~h}$ (blue), $3 \mathrm{~h}$ (blue stripes) and $1 \mathrm{~h}$ followed for $2 \mathrm{~h}$ in dark (black). Notice that for $\mathrm{CuO}_{\mathbf{x}} @ \mathrm{TiO}_{2} \mathbf{1 6 \%}$ yield was produced in the dark after UV exposure, while for $\mathrm{CuO}_{\mathbf{x}} @ \mathrm{Nb}_{2} \mathrm{O}_{5}$ the value is within experimental error.

We were surprised to discover that a "control" experiment at $525 \mathrm{~nm}$ leads to click products, albeit in yields after $4 \mathrm{~h}$ about 4 times lower than excitation at $368 \mathrm{~nm}$. This inspired exploratory experiments performed at longer wavelengths (594, 660 and $740 \mathrm{~nm})$. With the exception of excitation at $740 \mathrm{~nm}$, all LEDs can cause reaction, even after just 4h, although with decreasing yields at the longer wavelengths. This is summarized in the table $\mathrm{S} 1$ in the SI. Control experiments at $525 \mathrm{~nm}$ showed that $\mathrm{CuO}$ and $\mathrm{Cu}_{2} \mathrm{O}$ have no photocatalytic activity (See table $\mathrm{S} 1$ ). The lack of activity showed by $\mathrm{Cu}_{2} \mathrm{O}$ may be due to the small surface area available and $\mathrm{CuO}$ contamination (See figure S7 and S8). We speculate that under visible light irradiation, absorption by the smaller $\mathrm{CuO}$ particles (and thus with a larger band gap) leads to oxide mediated electron transfer to larger $\mathrm{CuO}$ particles, while the hole ultimately resides in the oxide support. This electron shuttle is illustrated in Figure $\mathrm{S} 11$ for $\mathrm{CuO}_{\mathrm{x}} @ \mathrm{TiO}_{2}$ and leads to $\mathrm{Cu}(\mathrm{I})$ in the larger $\mathrm{CuO}$ particles. Interestingly, in the mechanism proposed, polydispersity ultimately helps the photocatalytic process. The practical result is that the catalysts can be activated with visible light, and provides wavelength tunability of light-induced $\mathrm{Cu}$ AAC reaction without the use of organic photoinitiators. ${ }^{24}$

Interestingly, under argon the reaction stops at half of its normal yield (Figure 5 and Figure S11). Opening the vessel after reaching the plateau leads to increase the reaction yield up to almost $90 \%$ within $2 \mathrm{~h}$ of irradiation. This is likely due to an over reduction of the catalyst to $\mathrm{Cu}(0)$. The presence of $\mathrm{O}_{2}$ may play a role in the oxidation of both $\mathrm{Cu}(\mathrm{I})$ and $\mathrm{Cu}(0)$ keep- ing the catalytic cycle active as shown in the inset in Figure 5.21

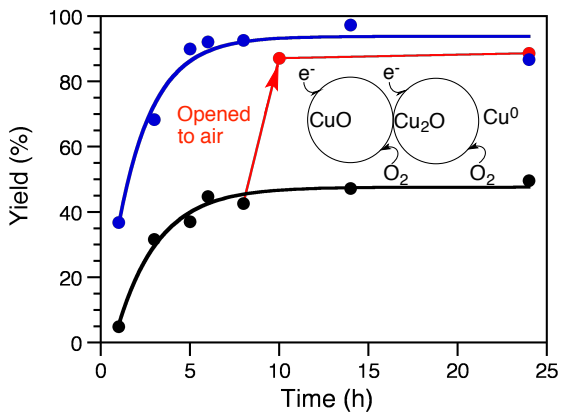

Figure 5. Study of the photocatalytic reaction of $1 \mathrm{a}$ and $2 a$ in $T H F$ in Ar (black) and in air (blue) using $\mathrm{CuO}_{\mathbf{x}} @ \mathrm{Nb}_{2} \mathrm{O}_{5}$. Red dots: yields obtained when system is exposed to air after $8 \mathrm{~h}$ of reaction under Ar. Inset: Role of the $\mathrm{O}_{2}$ in the $\mathrm{Cu}$ redox cycle.

Table 2 shows a study of the scope of this reaction varying the alkyne and the azide. Both catalyst show great versatility towards substituted phenyl alkynes with electron donor or electron withdrawing groups in position para, although $\mathrm{TiO}_{2}$ seems to work slightly better than $\mathrm{Nb}_{2} \mathrm{O}_{5}$ with ortho-substituted reactants. Further, the reaction can be extended for use with aliphatic alkynes, with $\mathrm{TiO}_{2}$ being quite effective, even with bulky reactants ( $c f$. entries 9 and 11). In the case of the azides studied, the catalysts proved useful towards different electronic demands, and only the aryl azide was inactive.

Finally, the reusability (Figure 6) of both catalysts was tested for the reaction of $1 \mathrm{a}$ and $2 \mathrm{a}$ in THF in air upon UVA irradiation for $6 \mathrm{~h}$, when the high yield plateau is reached for both $\mathrm{TiO}_{2}$ and $\mathrm{Nb}_{2} \mathrm{O}_{5}$-supported catalysts (Figure 3). We note that both catalysts show great stability after at least four reusability cycles. This stability can be explained by the continuous regeneration of $\mathrm{Cu}(\mathrm{I})$ upon light irradiation. ICP analysis of the crude of the reaction shows barely 0.01 and $0.002 \%$ of the available copper for the case of $\mathrm{CuO}_{\mathbf{x}} @ \mathrm{Nb}_{2} \mathrm{O}_{5}$ and $\mathrm{CuO}_{\mathrm{x}} @ \mathrm{TiO}_{2}$, respectively. These numbers suggest the release of $\mathrm{Cu}$ species during reaction is negligible, in accordance with the good performance of both catalysts during several catalytic cycles.

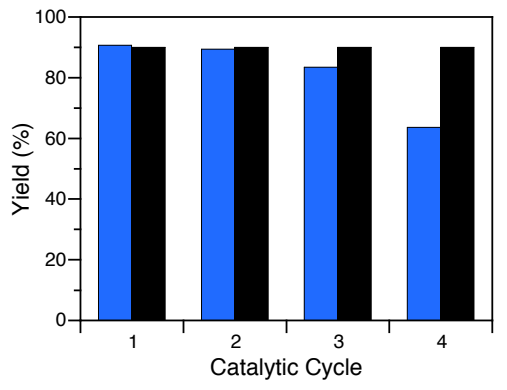

Figure 6. Reusability of $\mathrm{CuO}_{\mathbf{x}} @ \mathrm{TiO}_{2}$ (black) and $\mathrm{CuO}_{\mathbf{x}} @ \mathrm{Nb}_{2} \mathrm{O}_{5}$ (blue) as per conditions in table 2, entry 1.

In summary, we developed a new method to photocatalyze CuAAC under mild conditions and easy product isolation. We describe the use of two semiconductors as supports for copper nanoparticles, both showing excellent performance. $\mathrm{Nb}_{2} \mathrm{O}_{5}$ is a largely unexplored material sometimes employed as a strong acid, ${ }^{25}$ but rarely as a photocatalyst. In our system, the light is used to inject electrons to copper oxide from the semiconduc- 
tor. The catalyst can be reused several times because of the continuous generation of $\mathrm{Cu}(\mathrm{I})$ species under excitation of the semiconductor band gap. The catalyst is moisture tolerant and needs air and room temperature for optimal performance. The scope of the reaction has demonstrated the versatility of the catalysts extending their use to aliphatic alkynes.

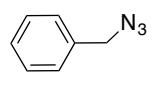

1a

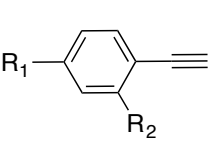

$\mathrm{R}_{3}=$

2a $\mathrm{R}_{1}=\mathrm{R}_{2}=\mathrm{H}$

2b $\mathrm{R}_{1}=\mathrm{OCH}_{3} \mathrm{R}_{2}=\mathrm{H}$

2c $\mathrm{R}_{1}=\mathrm{NH}_{2} \mathrm{R}_{2}=\mathrm{H}$

2d $R_{1}=\mathrm{HR}_{2}=\mathrm{NH}_{2}$

2e $\mathrm{R}_{1}=\mathrm{CN} \mathrm{R}_{2}=\mathrm{H}$

2f $\mathrm{R}_{1}=\mathrm{Cl} \mathrm{R} \mathrm{R}_{2}=\mathrm{H}$

Chart 1. Azides and alkynes included in Table 2.

Table 2. Scope of the photocatalytic GuAAC

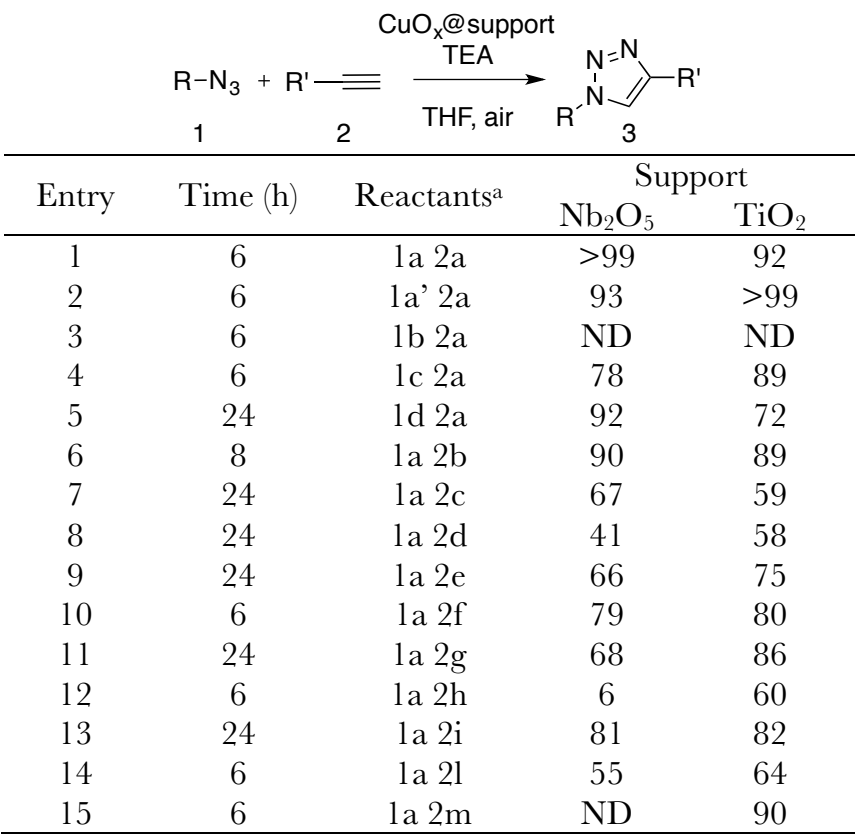

aSee Chart 1. Reaction conditions: $1-1.2 \mathrm{mmol}^{\%} \mathrm{of} \mathrm{Cu}$, azide/alkyne/amine (1:1:1), RT, UVA irradiation. Yields were calculated by ${ }^{1} \mathrm{H} \mathrm{NMR}$ in $\mathrm{CDCl}_{3}$.

Supporting Information. Experimental details, instrumentation used, as well as characterization of materials are shown in the supplementary information. The Supporting Information is available free of charge on the ACS Publications website.

\section{Corresponding Author}

* E-mail: titoscaiano@mac.com

*E-mail: anabel.lanterna@icloud.com

\section{Author Contributions}

†These authors contributed equally.

\section{ACKNOWLEDGMENT}

We thank the Natural Sciences and Engineering Research Council, the Canada Foundation for Innovation and the Canada Research Chairs program. BW thanks Beijing University of Chemical Technology for an International Joint Graduate-Training Program Scholarship.

\section{REFERENCES}

(1) Rostovtsev, V. V., Green, L. G., Fokin, V. V., Sharpless, K. B., Angew Chem. Int. Ed. 2002, 41, 2596-2599.

(2) Molteni, G., Bianchi, G., Marinoni, G., Santo, N., Ponti, A., New 7. Chem. 2006, 30, 1137-1139.

(3) Decan, M. R., Impellizzeri, S., Marin, M. L., Scaiano, J. C., Nat.Commun. 2014, 5 .

(4) Davies, I. W., Matty, L., Hughes, D. L., Reider, P. J., f. Am. Chem. Soc. 2001, 123, 10139-10140.

(5) Lipshutz, B. H., Taft, B. R., Angew. Chem. Int. Ed. 2006, 45, 8235-8238.

(6) Decan, M. R., Scaiano, J. C., 7. Phys. Chem. Lett. 2015, 4049-4053.

(7) Arumugam, S., Orski, S. V., Mbua, N. E., McNitt, C., Boons, G.-J., Locklin, J., Popik, V. V., Pure Appl. Chem. 2013, 85, 1499-1513.

(8) Tasdelen, M. A., Yagci, Y., Angew. Chem. Int. Ed. 2013, 52, 5930-5938.

(9) Adzima, B., Tao, Y., Kloxin, C., Deforest, C., Anseth, K., Bowman, C., Nature Chem. 2011, 3, 258-261.

(10) Katayama, T., Kamata, K., Yamaguchi, K., Mizuno, N., ChemSusChem 2009, 2, 59-62; Yamaguchi, K., Oishi, T., Katayama, T., Mizuno, N., Chem-Eur 7 2009, 15, 10464-10472.

(11) Pan, H., Renew. Sust. Ener. Rev. 2016, 57, 584-601; Ni, M., Leung, M. K. H., Leung, D. Y. C., Sumathy, K., Renew. Sust. Ener. Rev. 2007, 11, 401-425.

(12) Hashimoto, K., Irie, H., Fujishima, A., Japan f. Appl. Phys. 2005, 44, 8269 .

(13) Chassaing, S., Beneteau, V., Pale, P., Cat. Sci. \& Tech. 2016, 6, 923-957.

(14) Bandara, J., Udawatta, C. P. K., Rajapakse, C. S. K., Photochem. Photobiol. Sci. 2005, 4, 857-861.

(15) Gomes Silva, C., Juárez, R., Marino, T., Molinari, R., Garcia, H., 7. Am .Chem. Soc. 2011, 133, 595-602.

(16) Sabio, E. M., Chamousis, R. L., Browning, N. D., Osterloh, F. E., F. Phys. Chem. C 2012, 116, 19051-19051.

(17) Hoffmann, N., Aust. F. Chem. 2015, 68, 1621-1639.

(18) Lin, H. Y., Yang, H. C., Wang, W. L., Catal. Today 2011, 174, 106-113.

(19) Scaiano, J. C., Stamplecoskie, K. G., Hallett-Tapley, G. L., Chem. Commun. 2012, 48, 4798-4808.

(20) Alonso, F., Moglie, Y., Radivoy, G., Yus, M., Adv. Synth. Catal. 2010, 352, 3208-3214.

(21) Xu, L., Yang, Y., Hu, Z. W., Yu, S. H., Acs Nano 2016, 10 , 3823-3834.

(22) Hein, J., Fokin, V., Chem. Soc. Rev. 2010, 39, 1302-1315; Meldal, M., Tornoe, C. W., Chem. Rev. 2008, 108, 2952-3015; Pulkkinen, P., Shan, J., Leppanen, K., Kansakoski, A., Laiho, A., Jarn, M., Tenhu, H., Acs Appl Mater Inter 2009, 1, 519-525.

(23) Kulkarni, D., Wachs, S. E., Appl. Catal., A 2002, 237, 121 137.

(24) Tasdelen, M. A., Yilmaz, G., Iskin, B., Yagci, Y., Macromolecules 2012, 45, 56-61.

(25) Marin, M. L., Hallett-Tapley, G. L., Impellizzeri, S., Fasciani, C., Simoncelli, S., Netto-Ferreira, J. C., Scaiano, J. C., Catal. Sci. Tech. 2014, 4, 3044-3052. 
Insert Table of Contents artwork here

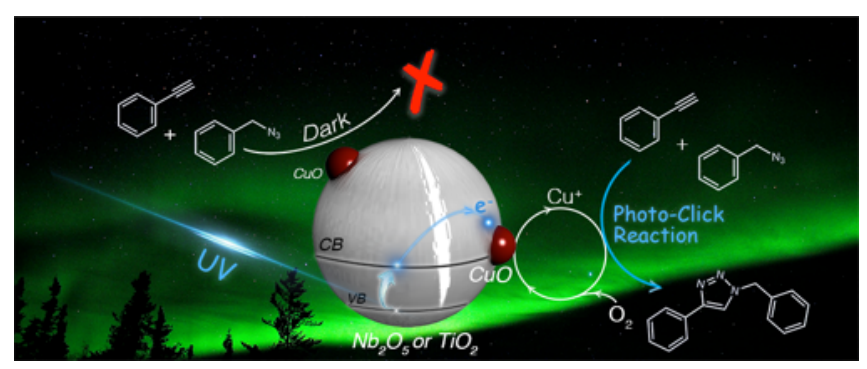

